\title{
Evaluation of Low Pressure Fogging System for Improving Crop Yield of Tomato (Lycopersicon esculentum Mill.): Grown under Heat Stress Conditions
}

\section{Danny Harel ${ }^{1, *}$, Hadar Fadida ${ }^{1}$, Shelly Gantz ${ }^{2}$, Kobi Shilo ${ }^{3}$ and Hagai Yasuor ${ }^{4}$}

1 Negev R \& D Center, M.P.O 4, Negev 8544100, Israel; E-Mail: hadarlab@mopdarom.org.il

2 Vegetable Department, Extension Services-Ministry of Agriculture, Bet-Dagan 5020000, Israel; E-Mail: shelly.gantz@gmail.com

3 Naan-Dan-Jain Irrigation Company, Naan 7682900, Israel; E-Mail: kobi_s@naandanjain.com

4 Plant Stress Physiology Lab, Gilat Research Center ARO, M.P.O Negev 8510500, Israel; E-Mail: hagai@volcani.agri.gov.il

* Author to whom correspondence should be addressed; E-Mail: danih@mopdarom.org.il; Tel.: +972-52-598-9769; Fax: +972-8-9985-201.

Received: 16 April 2013; in revised form: 29 May 2013 / Accepted: 1 June 2013 /

Published: 19 June 2013

\begin{abstract}
In Mediterranean regions, many tomato plants are grown throughout the hot summer period (May-September) in sheltered cultivation, mainly for plant protection reasons. Most of the shelters that are used are low cost net houses covered with 50 mesh insect proof net. In most cases these net houses have a flat roof and no ventilation or climate control measures. This insufficient ventilation during the hot summer leads to above optimal air temperatures and causes moderate heat stress inside the shelters, which leads to yield reduction. The aim of this study was to evaluate the ability of a simple and inexpensive low pressure fogging system installed in a naturally ventilated net house to lower temperatures and improve the yield during the summer. The study showed that in areas where relative air humidity $(\mathrm{RH})$ during the daytime is less than $60 \%$, tomato plants improved their performance when grown through the summer in net houses under moderate heat stress. Under fogging conditions pollen grain viability and fruit set were significantly improved. This improvement influenced the yield picked during September (104-136 DAP). However, total seasonal yield was not affected by the fogging treatment.
\end{abstract}


Keywords: low pressure fogging; tomato; heat stress; pollen viability; fruit yield

\section{Introduction}

Sensitivity of the reproductive stage to above optimal air temperature can cause reduction in fruit set and thus, the fruit yield for commercial tomato (Lycopersicon esculentum Mill.) growth [1]. Peet et al. [2] demonstrated that the daily mean temperature has a more significant influence on tomato production than the day or night temperature alone. At a daily mean temperature of $29{ }^{\circ} \mathrm{C}$, the fruit number, percentage fruit set and fruit weight per plant, decreased in comparison with that at $25{ }^{\circ} \mathrm{C}$. This reduction in yield is mainly due to impaired pollen and anther development, as well as reduced pollen viability $[3,4]$. For reasons of plant protection (mainly viral diseases spread by white fly), many tomato plots are grown in sheltered cultivation even in the Mediterranean regions, where the summer is hot and arid. Most of the shelters used during the summer are low cost net houses covered with 50 mesh insect proof net. In most cases, these net houses have flat roofs and no ventilation or climate control measures. This insufficient ventilation during summer leads to above optimal air temperature and creates moderate heat stress inside the shelters [5]. These conditions cause a reduction in fruit yield, as well as the grower profits. One way to cope with this situation is to use an inexpensive low pressure fogging system in the shelters during the hot season. This kind of evaporative cooling uses foggers that spray small droplets of water. The water evaporates and energy is lost from the air reducing its temperature together with increased humidity. Meca et al. [6] found that low pressure fogging systems can reduce air temperature and improve ball pepper yield grown in a greenhouse during the summer in the Mediterranean region. Other studies that tested low pressure fogging system efficiency emphasized the technical aspects of the issue [7-9] with less attention to vegetative parameters. While low cost fogging systems are an effective and important tool for many tomato growers in the Mediterranean region, little is known about their influence on tomato plant and yield under commercial growth conditions. Especially, little is known about their influence on pollen quality and the fertilization process. The aim of this study was to evaluate the ability of a low pressure fogging system installed in a naturally ventilated net house to lower temperatures and improve pollen quality, fruit set percentage and fruit yields during the hot Mediterranean summer.

\section{Results and Discussion}

\subsection{Fogging and Its Influence on Air Temperature and Relative Humidity}

Maximum air temperatures during the day time and minimum air temperatures during the night in all treatments (fogged, unfogged and outside the net house) are presented in Figure 1. Comparing day temperature (e.g., maximum air temperatures) in both treatments show a $2.5{ }^{\circ} \mathrm{C}$ reduction obtained by the fogging system during July and August (46-106 days after planting-DAP) while day and night temperatures reached their maximum value during this growing period. 
Figure 1. Description of daily maximum and minimum air temperatures in both treatments: Fogged, unfogged and outside the net house, starting at one day after planting (DAP) until the growth end 164 DAP.

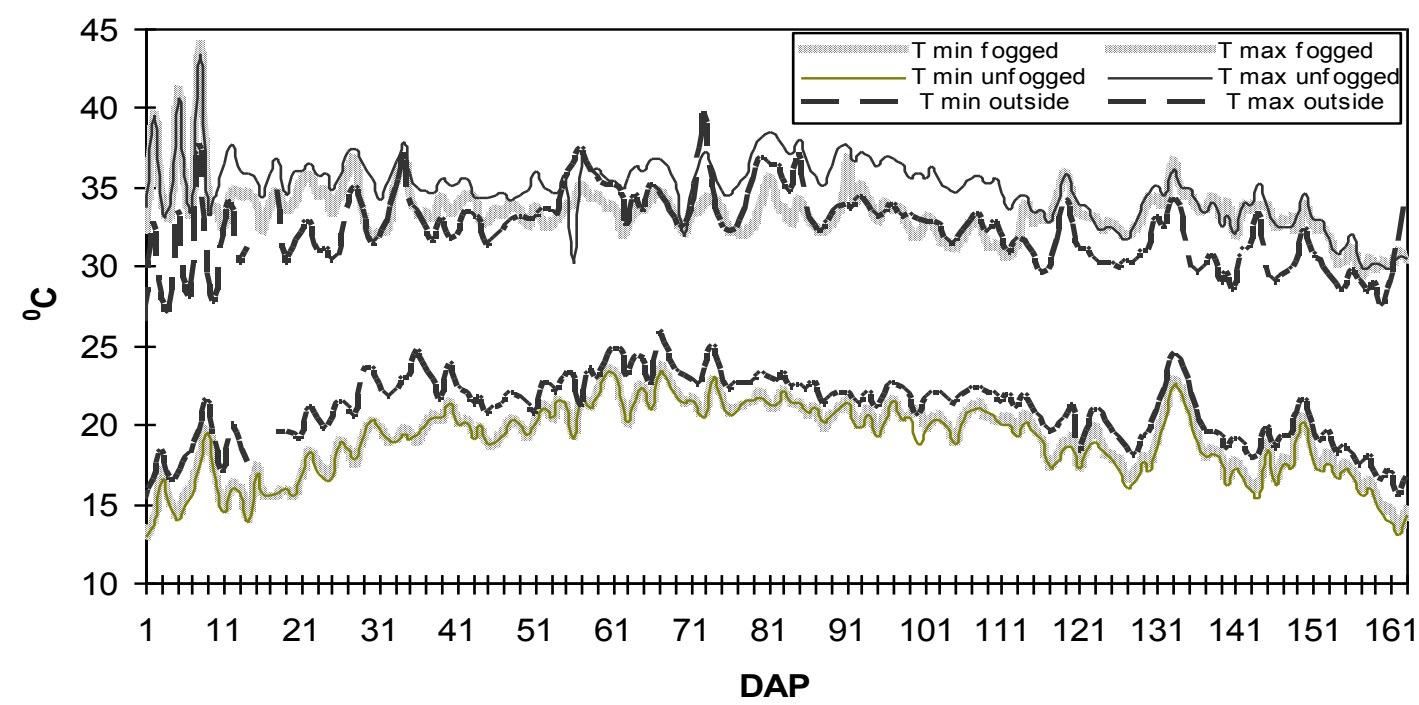

This reduction in day temperature leads to reduction of the mean daily temperature (Figure 2) reducing the daily mean air temperature by $1-1.5^{\circ} \mathrm{C}$ in the fogged net house, as compared to the unfogged conditions. Night temperatures were similar in both treatments.

Figure 2. Mean daily air temperature inside the net house during the growth period compared with the optimal mean daily air temperature for tomato growth.

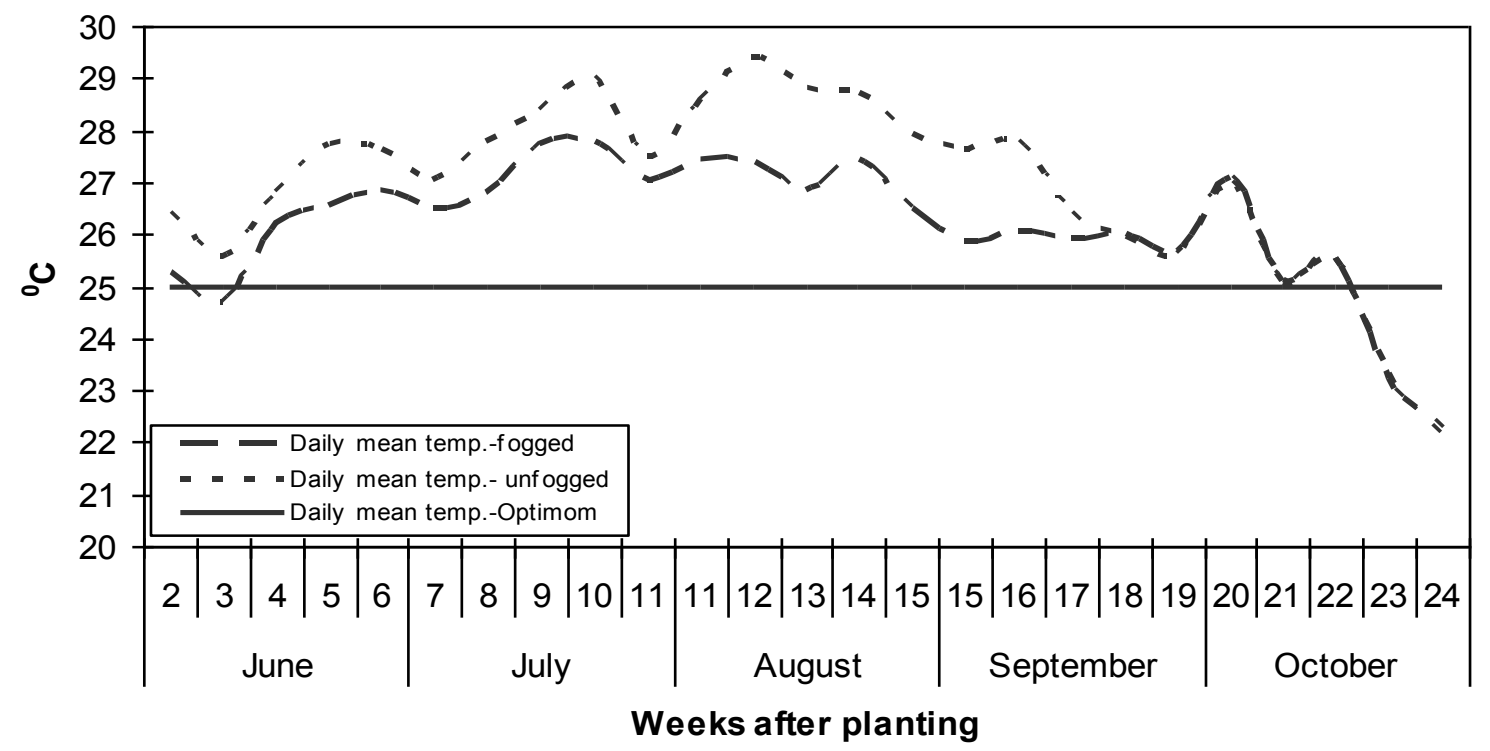

Figure 3 shows the relative humidity in the fogged, unfogged plots and the outside humidity during the daytime. Relative humidity increased by $14 \%$, on average, from $46 \%$ in the un-fogged plots to $60 \%$ in fogged plots. Figure 4 shows the relationship between relative air humidity in the unfogged 
treatment and the reduction in air temperature under fogging conditions. A second order polynomial equation describes the relationship with a regression coefficient of $R^{2}=0.53$. It can be seen that when $\mathrm{RH}$ is above $60 \%-65 \%$ the fogging system operation has only minor influence on the air temperature in the net house.

Figure 3. Maximum relative air humidity values during daytime in the fogged, unfogged plots and outside the net house throughout the growing season.

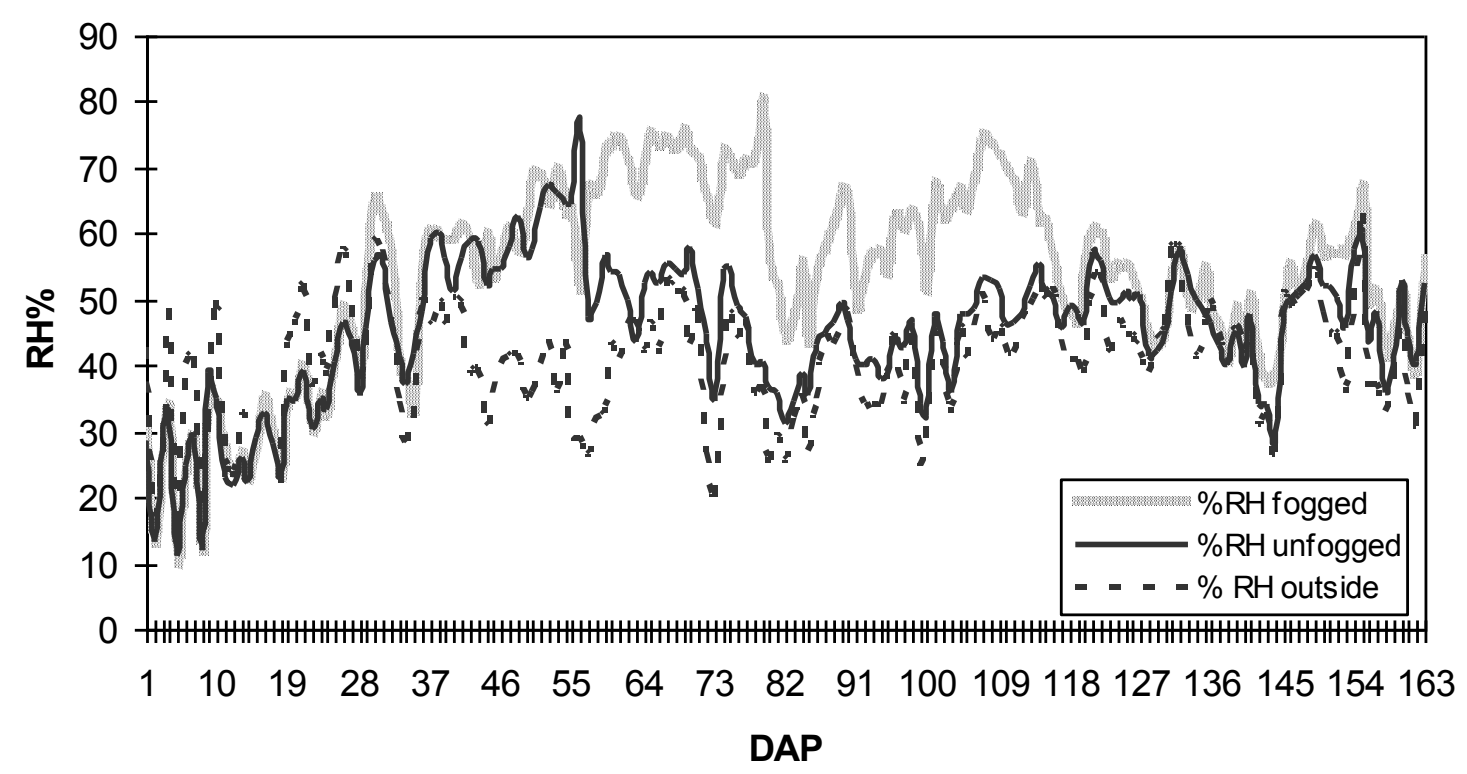

Figure 4. Relationship between relative air humidity in the unfogged treatment and the reduction in air temperature under fogging conditions. A second order equation that describes the relationship and its regression coefficient is presented in the figure.

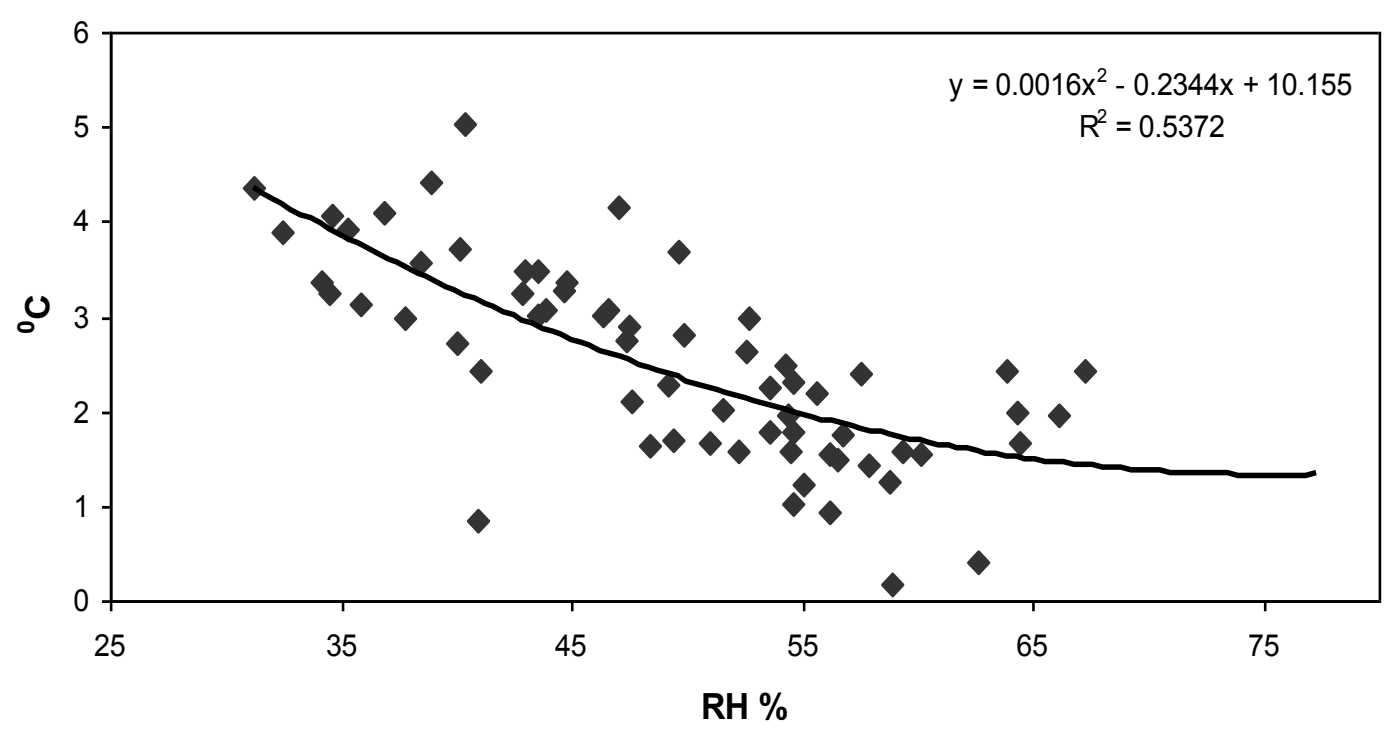




\subsection{Pollen Quality and Fruit Set Rates}

Pollen quality test results are show in Figure 5. Under fogging cooling conditions (Figure 5b) pollen viability increased by $26 \%$ in comparison with the unfogged plots (Figure $5 \mathrm{a}$ ), whilst the fraction of the non viable pollen grains decreased by $28 \%$.

Figure 5. Results of pollen quality tests: (a) Pollens collected in the unfogged plots;

(b) Pollens collected in the fogged plots.
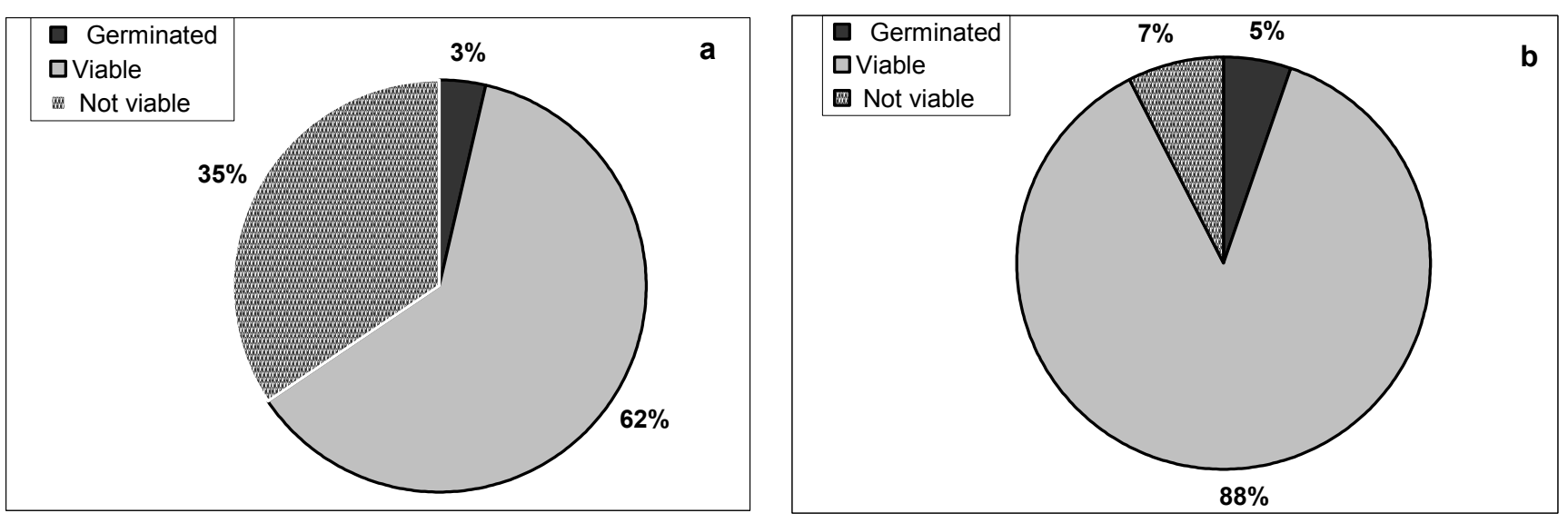

Fruit set rates from two sampling dates, 48 and 95 DAP are showed in Figure 6. On both dates the fruit set rates in the fogged plots were significantly higher in comparison with the unfogged plots ( $t=1.9, p=0.033, d f=25$ for the first date and $t=3.5, p=0.001, d f=24$ for the second date).

Figure 6. Fruit set rates from two sampling dates. Bars indicate standard error.

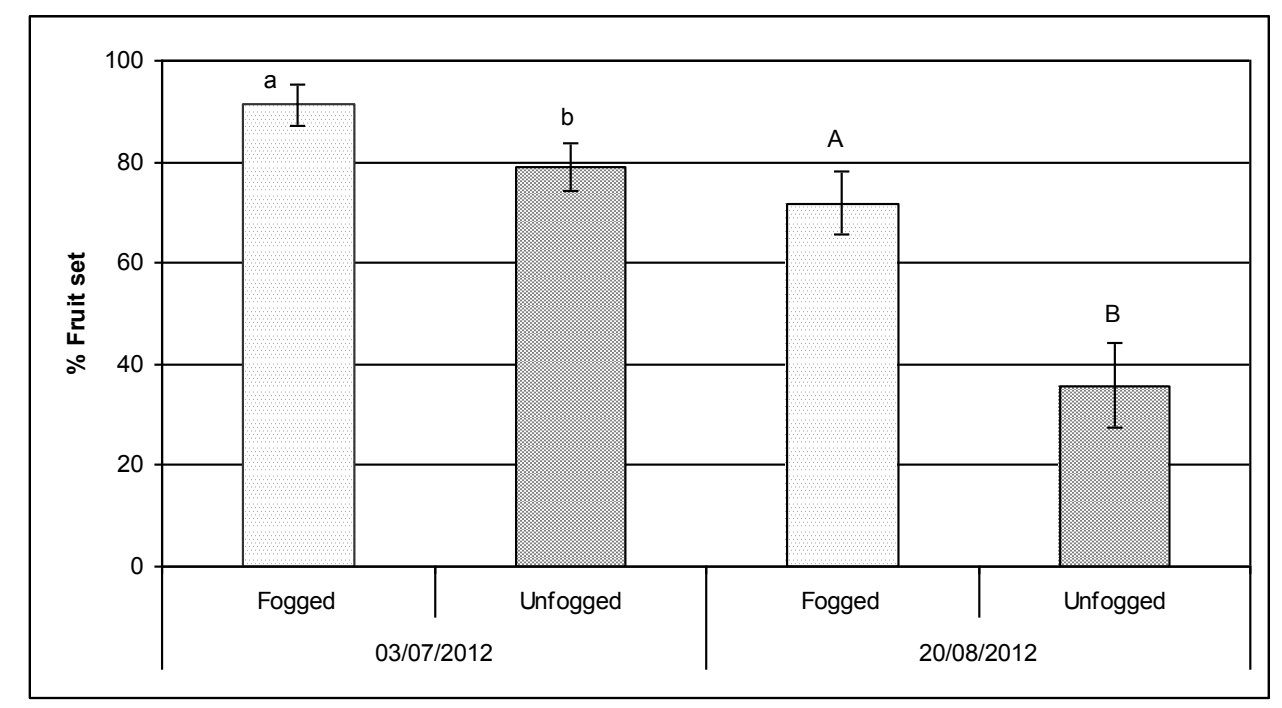

\subsection{Fruit Yield, Fruit Weight and Post Harvest Fruit Quality}

Total and market quality yield from fogged and unfogged plots is presented in Figure 7. No significant difference was found between the treatments. In Figure 8 the yield is presented and analyzed based on picking dates. Fruits produced during July, August and October did not differ 
between treatments. However, a significant difference was found between the treatments in the September yield when a higher yield was produced under fogging conditions, $(t=2.35, p=0.028$, $d f=5$ for total yield and $t=2.02, p=0.044, d f=4.47$ for market quality yield).

Figure 7. Amount of total yield, market quality yield, cracked and other unmarketable yield from fogged and unfogged plots. Bars indicate standard error.

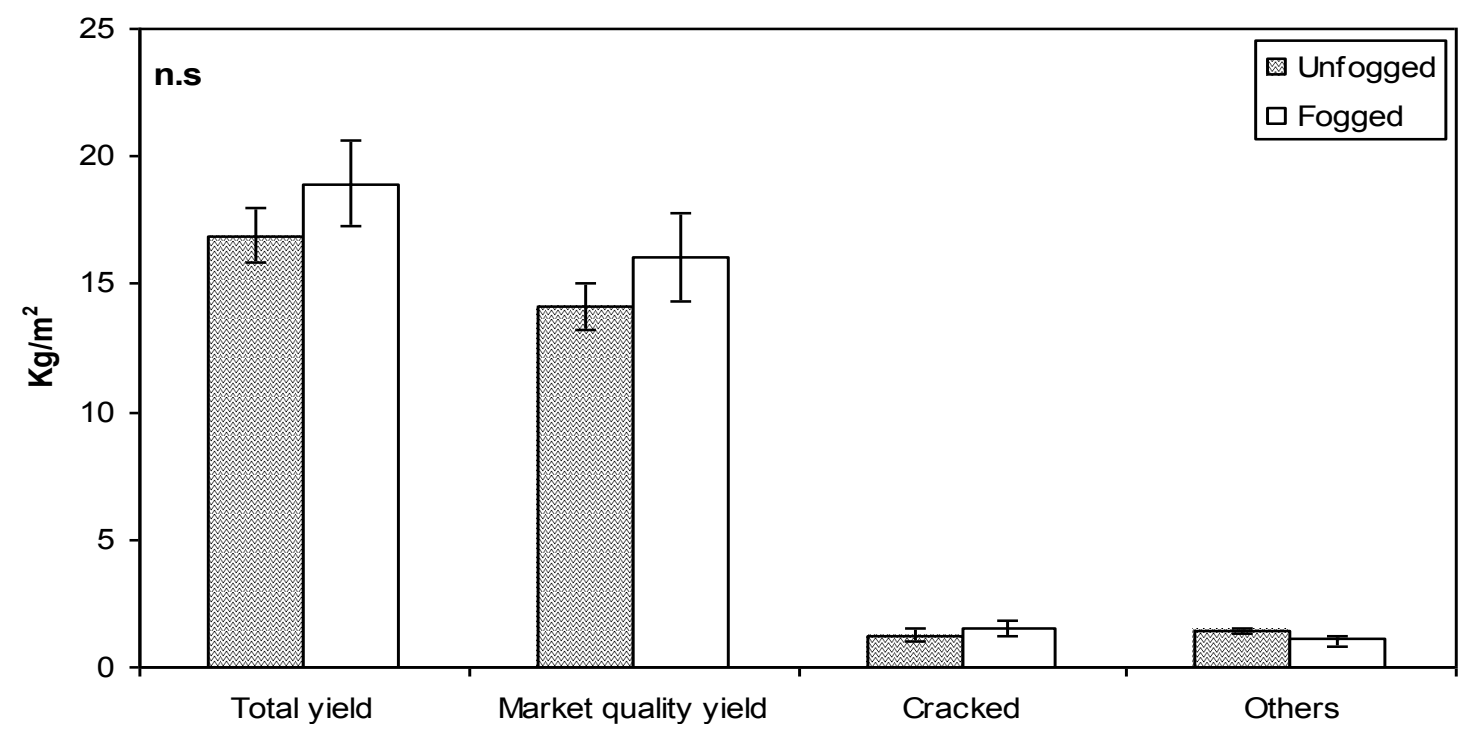

Figure 8. Amount of total yield and market quality yield presented based on picking dates. Bars indicate standard error. Significantly more yield was produced under fogging condition in September.

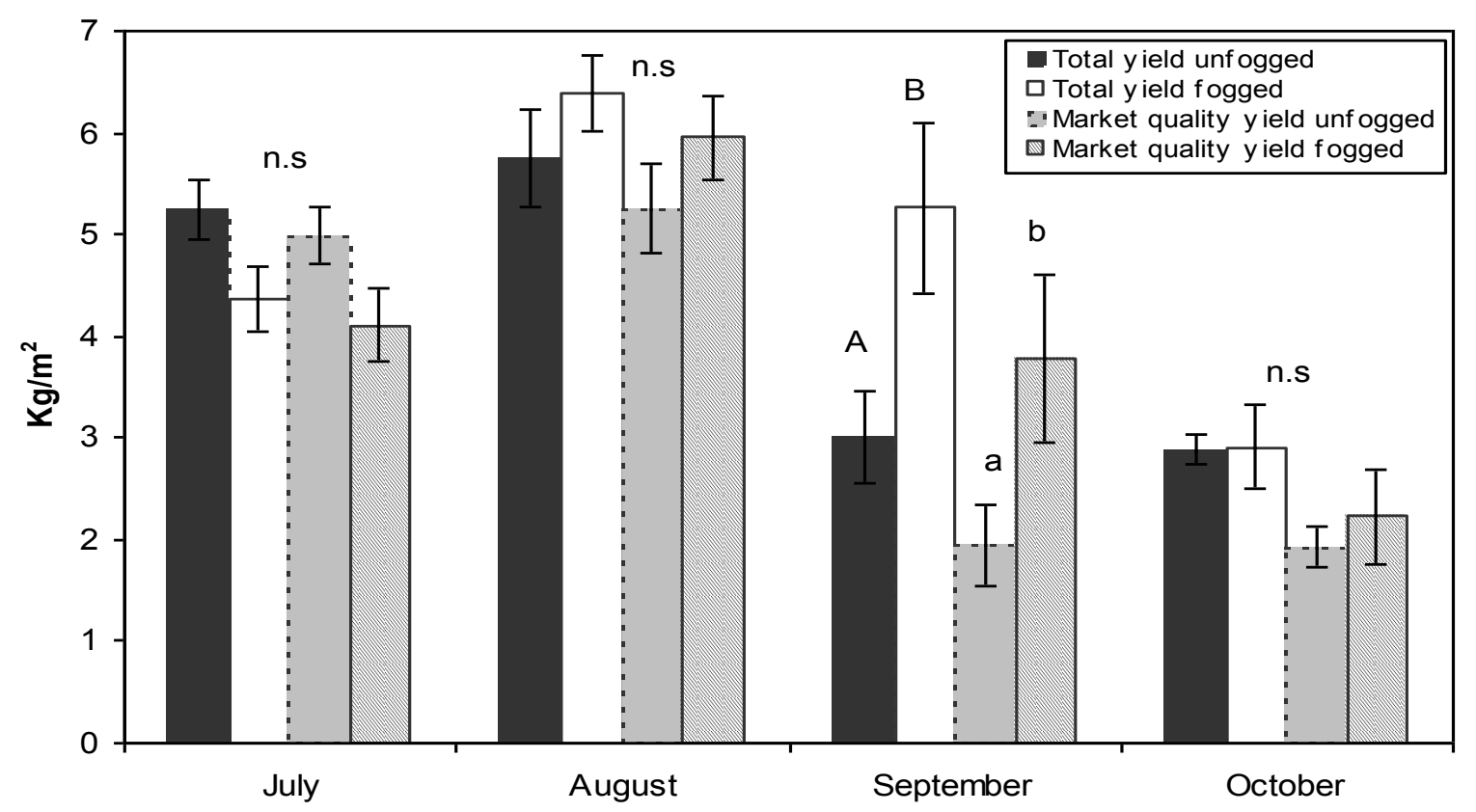


Mean fruit weight by picking dates is presented in Figure 9. A continuous trend of decline in fruit weight is detected but no significant difference was found between the treatments. The results from the post harvest test are shown in Table 1. More soft and rotten fruits were found in the fogged plots. However, in both treatments low quality scores were accepted. A possible reason for the low quality scores is that the 1125 tomato variety was used and is known to have relatively short shelf life and low quality after storage.

Figure 9. Mean fruit weight by picking dates. Bars indicate standard error.

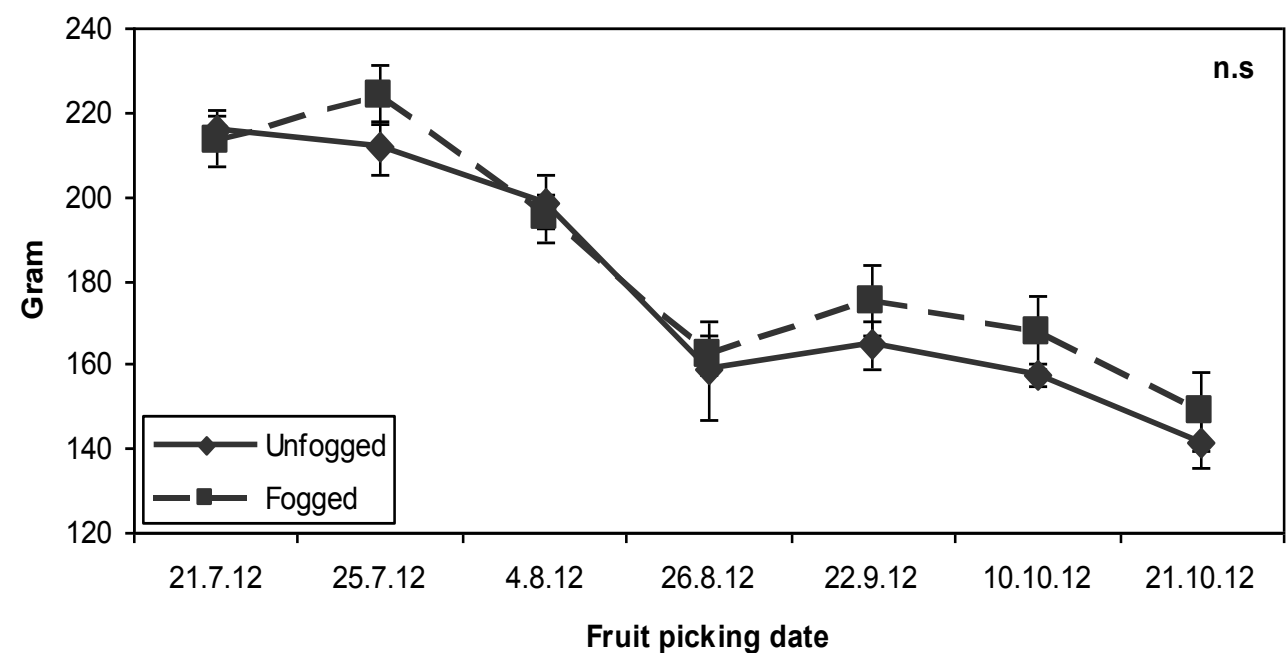

Table 1. Post harvest tests results.

\begin{tabular}{cccccccc}
\hline Treatment & Cracked & Firm & Flexible & Soft & Rotten & Irregular color & Fruit quality score \\
\hline & $\%$ & $\%$ & $\%$ & $\%$ & $\%$ & $\%$ & $(1-10)$ \\
Unfogged & 6.11 & 32 & 40 & 27 & 19 & 30 & 1.2 \\
Fogged & 10.6 & 27 & 38 & 35 & 27 & 36 & -0.8 \\
\hline
\end{tabular}

\subsection{Discussion}

Operation of low pressure foggers during tomato growth under suboptimal conditions, (high temperatures) succeeded in reducing the daily mean air temperature by $1-1.5^{\circ} \mathrm{C}$ (Figure 2 ). The reduction of the mean daily air temperature under fogging conditions with natural ventilation and $40 \%-60 \% \mathrm{RH}$ did not succeed in reaching the optimum mean daily temperature of $25^{\circ} \mathrm{C}$ (Figure 2). Nevertheless, this moderate reduction in heat stress improved pollen grain viability and fruit set ratio. This improvement in tomato pollen quality and fruit set under reduced heat stress is in agreement with several previous findings $[3,4]$. Total seasonal yield and market quality yield was not affected by the fogging operation. The cooling affect on yield can be detected only on the yield picked during September, e.g., fruit set in mid July to mid August. In the area where the trial was conducted air temperature is at its peak during July-August (Figure 1). It seems that the moderate reduction in mean daily air temperature under fogging conditions enabled the tomato to better cope with heat stress and to improve fruit set during July-August. However, this reduction in mean daily temperature did not affect fruit set occurring later on, during August and September (yield picked during October, Figure 7). 
Previous work demonstrated that continuous moderate heat stress $\left(2-3{ }^{\circ} \mathrm{C}\right.$ above optimal air temperature) can cause reduction in pollen production, pollen viability and fruit set [10,11]. With regard to the fact that the fogging system succeeded only in diminishing heat stress, those findings support the suggestion that the combination of chronic moderate heat stress together with relatively old plants (more than 3 months after planting) reduce the ability of the fogging system to improve the tomato yield. Low pressure fogging operation in green houses with natural ventilation was tested in several previous works. Those studies emphasized the importance of ventilation, low RH in the growth area [9] and its lower efficiency in comparison to high pressure systems [7]. However, neither study examined tomato reproductive parameters. The main gain in low pressure fogging compared to other evaporative cooling systems, like high pressure fogging and cooling pads, is in its technical simplicity and low price. This study demonstrated that under certain conditions (e.g., areas where $\mathrm{RH}<60 \%$ and plants that are two to three months after planting) tomato plants grown during the Mediterranean summer in net houses can better cope with moderate heat stress if a low pressure fogging system is operated. Under fogging conditions, heat stress was reduced, resulting in improvements in pollen quality, fruit set rates and higher fruit yield obtained during part of the fruit picking period.

\section{Experimental Section}

\subsection{Plant Cultivation}

The experiment was conducted at the Negev R \& D Center located in the southern part of the Israeli coastal plain $\left(34^{\circ} 23^{\prime} \mathrm{N}, 31^{\circ} 16^{\prime} \mathrm{E}, 104 \mathrm{~m}\right.$ above sea level). The climate in the region is Mediterranean with rainy winters (October-April) and prolonged dry hot summers. On 15 May, 2012, approximately 4 week old tomato var. 1125 (medium beef) transplants were hand-transplanted into the local sandy loam soil beds. Planting stand was 2200 plants $/ 1000 \mathrm{~m}^{2}$. Drip irrigation with complete chemical fertilizers in the irrigation water (fertigation) was used during the growth. Two weeks after transplanting each plant was connected to a Dutch style support system that rose up to $2.5 \mathrm{~m}$ height. Fruit picking started on 21 July, 2012, 65 days after planting (DAP) and ended on 11 November, 2012. The time between the fruit set and fruit picking was approximately 50 days.

\subsection{Net House, Fogging System and Climate Data Collection}

The trial took place in a naturally ventilated, north/south oriented net-house with a gutter height of $4 \mathrm{~m}$, a ridge height of $4.5 \mathrm{~m}$ and a double slope roof. The net house was covered (roof and walls) with 50 mesh insect proof net. A commercially available low pressure fogging system (Naan-Dan-Jain, Naan, Israel) was installed in the net house on a $700 \mathrm{~m}^{2}$ area. The system consisted of nozzles (Super fogger $13 \mathrm{~L} / \mathrm{h}$, Naan-Dan-Jain, Naan, Israel) configured in rows. The nozzle rows were stabilized by the net house steel framework $3.5 \mathrm{~m}$ from the ground. The nozzle sections were $1.5 \mathrm{~m}$ apart per row and $2.7 \mathrm{~m}$ apart between the rows. A water reservoir and a booster pump maintained the line pressure at $405 \mathrm{kPa}$. Anti drip devices at every nozzle prevented dripping once the line pressure dropped below $253 \mathrm{kPa}$. A simple automatic control (Fog-control, Talgil, Israel) controlled the system operation through a solenoid valve. The control was set to operate the fogging system when the air temperature inside the net house at the plant canopy height rose above the threshold of $30^{\circ} \mathrm{C}$. The system operation 
was stopped when air temperature reached $28^{\circ} \mathrm{C}$. Fog intervals were set by trial and error to minimize excessive wetting while trying to maximize cooling effect. After several attempts, a fog interval was set at $5 \mathrm{~s}$ with a $20 \mathrm{~s}$ break between the intervals.

Analysis of the water used by the fogging system is presented in Table 2. The fogging system operation started 15 DAP (30/5/12) and ended 117 DAP (11/9/12). This corresponded to the end of the hot season in the growth area. Un-fogged (control treatment) plots were grown in identical conditions apart from the absence of fogging system.

Table 2. Analysis results of the water used by fogging system.

\begin{tabular}{cccccc}
\hline $\mathbf{E C}$ & $\mathbf{P H}$ & $\mathbf{C l}$ & $\mathbf{C a}$ & $\mathbf{C a C O}$ & $\mathbf{M g}$ \\
\hline$(\mathrm{ds} / \mathrm{m})$ & & $(\mathrm{mg} / \mathrm{L})$ & $(\mathrm{mg} / \mathrm{L})$ & $(\mathrm{mg} / \mathrm{L})$ & $(\mathrm{mg} / \mathrm{L})$ \\
0.5 & 7.2 & 68 & 32 & 110 & 7.31 \\
\hline
\end{tabular}

The temperature and relative humidity $(\mathrm{RH})$ inside the net house within or just above the plant canopy (1.5 $\mathrm{m}$ from ground) were monitored with Hobo ZW-003 RH/Temp data loggers (Onset Computer Corporation, Bourne, MA, USA). The temperature and relative humidity from the net house surroundings were obtained from a meteorological station located nearby the trial location.

\subsection{Mature Pollen Quality}

Mature pollen was extracted, stained and counted according to Pressman et al. [12]. Ten flowers at the first day of anthesis were collected from both treatments. One anther was removed from each flower and placed in a microfuge tube containing $0.5 \mathrm{~mL}$ of germinating solution that contained $100 \mathrm{~g} \cdot \mathrm{L}^{-1}$ sucrose, $2 \mathrm{mM}$ boric acid, $2 \mathrm{mM}$ calcium nitrate, $2 \mathrm{mM}$ magnesium sulfate and $1 \mathrm{mM}$ potassium nitrate. Pollen grains were released from the anthers by shaking the tubes well. Tubes were then placed in an incubator at $20{ }^{\circ} \mathrm{C}$ for $4 \mathrm{~h}$, after which a drop of Alexander dye (Alexander 1980) was added to the solution. Numbers of germinated, non-germinated but viable (stained purple), and non-viable (stained green) pollen grains were recorded for each flower. The above described procedure was repeated three times, and average results were calculated.

\subsection{Fruit Quality and Post Harvest Tests}

Post harvest tests were made immediately after fruit picking. Fruit was refrigerated in accordance with simulated commercial storage protocol, 5 days at $12{ }^{\circ} \mathrm{C}, 96 \% \mathrm{RH}$ and then for 3 days at $20{ }^{\circ} \mathrm{C}$. At the end of the storage period the fruit was examined for the following parameters: Cracked, firm, flexible, soft, rotten and irregular color. From these parameters post harvest fruit quality score was calculated by weighing the parameters with $50 \%$ for firmness, $40 \%$ for cracks and $10 \%$ for color regularity. 


\subsection{Data Analysis}

Student's $t$ test was used to determine statistical significance between the fogged and unfogged treatments in fruit set and fruit yield. The analyses were conducted using the statistical package JMP 8 (SAS Institute Inc., Cary, NC, USA).

\section{Conclusions}

This study showed that in growth areas where $\mathrm{RH}<60 \%$, tomato plants grown throughout the Mediterranean summer in net houses can better cope with moderate heat stress during the two to three months after planting if a low pressure fogging system is operated. This improvement is expressed mainly in higher pollen quality and fruit set rates. Higher fruit yield was obtained only during part of the fruit picking period.

\section{Acknowledgments}

We wish to thanks Myron Sofer, Alik Slepoy, Liana Ganot, Rami Golan and Dovi Zohar from the Negev R \& D Center for their help in conducting this experiment. We also thank the vegetable committee of Israel for the financial support.

\section{Conflicts of Interest}

The author declares no conflict of interest.

\section{References}

1. Pressman, E.; Peet, M.M.; Pharr, D.M. The effect of heat stress on tomato pollen characteristics is associated with changes in carbohydrate concentration in the developing anthers. Ann. Bot. 2002, 90, 631-636.

2. Peet, M.M.; Willits, D.H.; Gardner, R. Response of development and post-pollen production processes in sterile tomatoes to chronic sub-acute high temperature stress. J. Ex. Bot. 1997, 48, $101-111$.

3. Sato, S.; Peet, M.M.; Thomas, J.F. Determining critical pre-and post-anthesis periods and physiological processes in Lycopersicon esculentum Mill. exposed to moderately elevated temperatures. J. Ex. Bot. 2002, 53, 1187-1195.

4. Sato, S.; Kamiyama, M.; Iwata, T.; Makita, N.; Furukawa, H.; Ikeda, H. Moderate increase of mean daily temperature adversely affects fruit set of Lycopersicon esculentum by disrupting specific physiological processes in male reproductive development. Ann. Bot. 2006, 97, 731-738.

5. Baille, A. Overview of greenhouse climate control in the Mediterranean regions. Cahiers Op. Available online: http://om.ciheam.org/om/pdf/c31/CI020831.pdf (accessed on 16 June 2013).

6. Meca, D.; López, J.C.; Gázquez, J.C.; Baeza, E.; Pérez Parra, J.; Zaragoza, G. Comparison of three different cooling systems in parral type greenhouses in Almería. Span. J. Agric. Res. 2007, $5,285-292$. 
7. Li, S.; Willits, D.H. Comparing low-pressure and high-pressure fogging systems in naturally ventilated greenhouses. Bios. Eng. 2008, 101, 69-77.

8. Li, S.; Willits, D.H.; Yunker, C.A. Experimental Study of Low Pressure Fogging System in Naturally Ventilated Greenhouses. American Society of Agricultural and Biological Engineers: St. Joseph, MI, USA, 2005.

9. Öztürk, H.H. Evaporative cooling efficiency of a fogging system for greenhouses. Turk. J. Agric. For. 2003, 27, 49-57.

10. Vara-Prasad, P.V.; Craufurd, P.Q.; Summerfield, R.J. Fruit number in relation to pollen production and viability in groundnut exposed to short episodes of heat stress. Ann. Bot. 1999, 84, 381-386.

11. Sato, S.; Peet, M.M.; Thomas, J.F. Physiological factors limit fruit set of tomato (Lycopersicon esculentum Mill.) under chronic, mild heat stress. Plant Cell Environ. 2000, 23, 719-726.

12. Pressman, E.; Moshkovitch, H.; Rosenfeld, K.; Shaked, R.; Gamliel, B.; Aloni, B. Influence of low night temperatures on sweet pepper flower quality and the effect of repeated pollinations, with viable pollen, on fruit setting. J. Hortic. Sci. Bio. 1998, 73, 131-136.

(C) 2013 by the authors; licensee MDPI, Basel, Switzerland. This article is an open access article distributed under the terms and conditions of the Creative Commons Attribution license (http://creativecommons.org/Licenses/by/3.0/). 